\title{
Drug Formulation Process, Not Otherwise Specified
}

National Cancer Institute

\section{Source}

National Cancer Institute. Drug Formulation Process, Not Otherwise Specified. NCI

Thesaurus. Code C112970.

A process that forms a dosage that is not otherwise specified. 